Bidik: Jurnal Pengabdian kepada Masyarakat | Vol. 2 No. 1 Oktober 2021

Doi: https://doi.org/10.31849/bidik.v2i1.7993

\title{
Membaca Puisi Arab Sebagai Cara Mencintai Bahasa Arab
}

\author{
Muhammad Walidin*, Faqihul Anam, Masyhur, Munandar \\ Prodi Bahasa dan Sastra Arab \\ Fakultas Adab dan Humaniora, Universitas Islam Negeri Raden Fatah Palembang \\ *Email: Muhammadwalidin_uin@radenfatah.ac.id
}

\begin{abstract}
Arabic poetry is well known since thousands years ago (500 AC). It is a medium of expression, entertainment, and information for Arab people. Arabic poetry also attracts many people for it's rythmic and ryhme patterns, both people in common and scientific community. So, this Community Service Program beld by Department of Arabic Literature, Faculty of Adab and Humanities, UIN Raden Fatah Palembang tried to make Arabic Poetry Reading as a way to motivate students to love Arabic more. Furthermore, the students felt motivated after hearing the poetry reading to learn Arabic as the sixt language of United Nations.
\end{abstract}

Keywords: Arabic Poetry, rythme and rybme

\begin{abstract}
Abstrak
Puisi Arab telah berumur ribuan tahun. Keberadaannya sebagai media ekspresi, hiburan, dan informasi membuat puisi terus bertumbuh hingga sekarang. Keindahan puisi Arab dengan pola ritme dan sajak juga menarik banyak orang, baik masyarakat awam maupun masyarakat ilmiah. Program pengabdian kepada masyarakat ini mencoba menjadikan pembacaan puisi Arab sebagai cara untuk memotivasi pelajar agar lebih mencintai bahasa Arab. Penerima sasaran PKM mendapatkan manfaat dari program ini dengan tumbuhnya kecintaan pada bahasa Arab setelah mendengar pembacaan puisi Arab yang merdu secara musikalitas.
\end{abstract}

Kata kunci: puisi Arab, wazan dan qafiyah, motivasi

\section{Pendahuluan}

Bahasa Arab merupakan bahasa yang tergolong dalam bahasa Semit. Ia berkerabat dengan bahasa Ibrani, Arami, Punisia, Babilonia atau Asyiria, dan Ethiopia. Dibandingkan dengan bahasa kerabatnya, Bahasa Arab memiliki lebih banyak penutur, yakni sekitar 422 juta jiwa pada saat ini. Para penutur bahasa Arab modern ini tinggal di 26 negara, khususnya Asia Barat dan Afrika Utara. Berkaitan dengan banyak penutur bahasa Arab di seluruh dunia, pada tanggal 18 Desember 1973, PBB menjadikan bahasa ini sebagai bahasa internasional ke 6, setelah bahasa Inggris, Tionghoa, Perancis, Rusia, dan Spanyol. 
Bahasa Arab, sebagaimana bahasa lainnya adalah media komunikasi yang digunakan oleh penuturnya sesuai dengan kesepakatan yang dibuat. Bahasa adalah sistem lambang bunyi ujaran yang arbitrer yang dipakai sebagai media komunikasi oleh masyarakat penggunanya. Sifatnya yang arbiter itulah yang membuat bahasa bahasa menjadi unik, sebagaimana dikatakan oleh Ronald Wardhaugh. Para penutur Indonesia menyebut kayu yang didisain untuk duduk sebagai bangku atau kursi. Sementara masyarakat Arab menyebutnya maq'ad atau kursiyun. Di negara-negara yang menggunakan bahasa inggris, para penuturnya menyebut benda yang memiliki fungsi demikian dengan nama chair. Demikianlah berbagai pengungkapan sesuatu secara berbeda dalam berbagai bahasa karena bahasa adalah sistem lambang atau simbol bunyi yang berkembang berdasarkan suatu aturan yang disepakati oleh pemakainya. Setiap lambang bahasa memiliki makna atau konsep. Oleh karena itu, dapat disimpulkan bahwa setiap suatu ujaran bahasa memiliki makna.

Bahasa bersifat universal dan tidak terikat dengan agama tertentu, tetapi lebih merujuk pada sikap nasionalisme. Demikian juga dengan bahasa Arab, ia digunakan oleh 422 juta jiwa dengan latar agama yang beragam. Kalaupun bahasa Arab banyak dikaitkan dengan kitab suci ummat Islam, hal ini adalah sebuah keberuntungan bagi bahasa Arab karena al-Qur'an menghindarkan bahasa ini dari proses kepunahan.

Saat ini, bahasa Arab semakin digandrungi para pelajar karena fungsi bahasa Arab sebagai media komunikasi yang digunakan untuk berbagai keperluan. Para pelajar yang beragama Islam cenderung belajar bahasa Arab untuk memahami warisan keilmuan klasik yang adiluhung dan tertulis dalam bahasa Arab. Sebagaimana kita ketahui, Islam mengalami masa keemasan sejak masa dinasti Umayyah di Timur (90 tahun), Dinasti Umayyah di Barat (275 tahun), Dinasti Abbasiyah (750-1250 M), dan masa kebangkitan (sejak 1798). Banyak karya-karya avant garde intelektual muslim yang dicatat dalam bahasa Arab (Siti Maryam, 2002:79-147). Bagi para calon pekerja untuk kawasan Timur Tengah, Bahasa Arab akan menarik untuk dipelajari sebagai media komunikasi yang mempermudah pekerjaan. Bagi para pelancong, bahasa Arab digunakan untuk menjalin komunikasi dengan warga setempat dan memahami aturan yang berlaku di tempat tersebut.

Berbagai metode telah digunakan para sarjana untuk membuat pelajaran bahasa Arab menjadi mudah. Metode tersebut secara formal dapat dipelajari di berbagai lembaga pendidikan formal (sekolah di bawah Kementerian Agama) atau nonformal (kursus, program sandwich, program magang). Pola pembelajaran bahasa Arab di berbagai tempat tersebut kiranya masih perlu ditunjang dengan berbagai motivasi agar para pelajar/pengguna semakin cinta dengan bahasa Arab.

Salah satu motivasi agar para pelajar mencintai bahasa Arab adalah dengan mengajarkan keindahan bahasa Arab melalui pembacaan puisi Arab. Puisi Arab pada hakekatnya terbagi dalam dua kategori, pertama adalah puisi konvensional/tradisional (shi'r multaz\}am/qadi $>m$ ) dan kedua adalah puisi bebas (shi'r mursal). Dalam definisi puisi konvensional, as-shi'r (الثشر) berarti ucapan atau tulisan yang memiliki waz\} an (ritme) dan qa>fiyah (rima). Waz\} an yang berati timbangan adalah polapola tertentu yang disebut dengan Bab\}ar atau matra/metrum/ritme. Ada 16 jenis bah\}ar yang dipelajari dalam ilmu $A r u>d\}$, yaitu ilmu yang mempelajari benar tidaknya timbangan sy'ir dan kemungkinan hal aneh dan cacat dalam bah\}ar tersebut (Wajih, 2006: 11-12). Penggunaan waz\}an dan qa $>$ fiyah dalam puisi tradisional Arab hukumnya adalah wajib, bila ia ingin disebut sebagai puisi. Bila tidak, maka ia hanya bisa disebut sebagai prosa (Wajih, 2006: 13). Adapun bab\}ar yang dimaksud 
adalah bah\}ar basi>t\}, t\}awi>l, rajz, ka>mil, ramal, madi>d, khafi>f, wa>fir, mutada>rik, hazaj, mutaqa $>$ rib, sari> ', khafif, muns \}arih, mud\}a $>$ ra', muqtad $\} a b$ (Umam, 1990: 4).

Bila dibandingkan dengan puisi lama Indonesia, terdapat kesamaan definisi. Wirjosoedarmo dalam (Pradopo, 1997: 5) mengemukakan definisi puisi yaitu karangan yang terikat oleh: 1) banyak bait dalam tiap baris (kuplet/strofa, suku karangan), 2) banyak kata dalam setiap baris, 3) banyak suku kata dalam setiap baris, 4) rima, dan 5) irama. Sayangnya, definisi ini sudah tidak cocok lagi bagi puisi zaman sekarang sehingga sulit untuk menjumpai puisi seperti ini di Indonesia. berbeda dengan puisi Arab, Penggunaan pola timbangan yang ketat dalam puisi Arab konvensional sudah sangat akrab di telinga masyarakat Arab. Hal ini telah berlangsung sejak zaman jahiliyah (500 M) hingga masa kebangkitan sastra Arab modern (1805 saat Muhammad Ali Pasha berkuasa). Bahkan, hingga kini sebenarnya puisi Arab konvensional masih terus hidup karena keunikan dan keindahan polanya.

Seperti juga puisi Indonesia yang mengalami pembaharuaan di era Angkatan 1945, sastra Arab juga mengalami perubahan tersebut lebih awal. Saat kedatangan Perancis ke Mesir pada tahun 1798-1801, kesusastraan Arab bersinggungan dengan sastra Barat. Tersebab pengaruh kesusastraan Barat ini, sastra Arab akhirnya mengenal puisi bebas (al-sh'ir al-Mursal). Puisi ini tidak terikat lagi dengan prosodi/matra gaya lama. Secara bentuk lebih dekat kepada prosa sastra, enjambementnya tidak lagi berbentuk dua baris sejajar (bait) sebagaimana qasidah, tetapi tersusun ke bawah seperti juga puisi Indonesia modern. Para pelopor puisi bebas ini termasuk di antaranya adalah Ahmad Zaki Abu Syadi (1892-1955), pemimpin aliran madrasah Apollo di Mesir dan tiga serangkai madrasah diwan (1921), Abbas Mahmud al-'Aqad (1889-1964), Abd al-Rahman Syukri (1889-1958), dan Ibrahim Abd alQadir al-Mazini (1890-1949). Tapi ada juga yang mengatakan bahwa pelopor puisi bebas ini adalah penyair perempuan Irak bernama Nazik al-Malaikah (1923-1970) dalam puisinya Qasi>dah al$K u>l i>r a$ (Senandung Kolera) yang terbit terbit tahun 1947.

Aliran-aliran pembaharu ini terinspirasi dengan tokoh sentral pembaharuan sastra Arab, yaitu Khalil Mutran (1872-1949). Khalil Mutran adalah penyair kelahiran Lebanon yang tinggal di Mesir. Ia merupakan orang pertama yang mengembangkan aliran romantik dalam perpuisian Arab. Ia terpengaruh dengan puisi romantik Prancis, terutama puisi-puisi naratif Hugo, lirik-lirik Mussel dan Baudelaire (Andangdjaja, 1983: 19). Hal ini karena ia lama tinggal di Perancis dan mempelajari sastra Perancis. Alhasil, Syair-syairnya pasca kepulangannya ke Mesir menjadi sangat bercorak romantik, bersifat individualistik, introspekstif, dan ekspresif. Ia lebih memprioitaskan makna makna dalam puisi-puisinya ketimbang bentuk. Ia memerangi despotisme, kezaliman, diskriminasi kelas, kebodohan, ketimpangan sosial, dan memperjuangkan kemajuan dan kebebasan berpikir (Andangdjaja, 1983: 19). Khalil Mutran dengan berani mendobrak dominasi puisi Arab konvensional dan membebaskan diri darinya. Ia berhasil menghancurkan pola prosodi (qasidah) berbasis waz\}an dan qa>fiyah melalui karya-karya progresifnya. Kemudian, barisan pembaharu ini diperkuat oleh Khalil Jibran (lahir 1883), Adonis (lahir 1930), Khalil Hawi (lahir 1925), Fadwa Tuqan (lahir 1917), dan Nizar Qabbani (lahir 1923), dan masih banyak lagi penyair lainnya (Sukron Kamil, 2009: 16-18).

Sebagaimana disebutkan pada bagian di atas bahwa puisi Arab konvensional adalah unik dan indah. Keindahan puisi ini bermula dari diksi yang tepat untuk menghasilkan efek musikalitas. Sebuah bait puisi akan mempertimbangkan potongan-potongan irama (taqti $>$ '), satuan suara (terdiri dari vokal dan konsonan), satuan irama (al-tafilah), irama (wazn), kecepatan irama (zib\}a $>f$ ), cacat 
irama ('illat), yang terangkum dalam metrum/lagu (al-bah\}r, serta diakhiri dengan sajak (qa $>$ fiyah). Qa $>$ fiyah adalah kata terakhir pada bait syair, yang dihitung mulai dari huruf yang terakhir pada bait sampai dengan huruf hidup sebelum huruf sukun yang ada di antara kedua huruf hidup tersebut (Habibie, 2018:114).

Karena susahnya menulis puisi Arab, tak heran bila Shauqi D \}aif menyatakan bahwa memproduksi puisi itu bukalah perkara mudah (D \}aif, 1943:13). Bayangkan bila ini puisi Arab terdiri dari ratusan bait, maka adalah hal yang sulit bagi penyair untuk memilih diksi dengan irama yang sama untuk makna yang dimaksudkan. Dan bila berhasil ditulis, maka hal itu akan menunjukkan kehebatan pernyairnya. Kesulitan para penyair dalam menulis puisi Arab akan terbayarkan dengan apresiasi masyarakat pembaca/pendengar yang terbujuk lena oleh keindahan musikalitasnya. Oleh karena itulah, pembacaan puisi Arab dengan segala keindahannya dapat digunakan sebagai motivasi pelajar untuk mencintai bahasa Arab.

\section{Pedekatan Pelaksanaan Program}

PKM kali ini dilakukan dengan kombinasi pendekatan lecturing, Performance, dan small group discussion. Pada tahap lecturing, seorang mahasiswa sebagai presenter memberikan penjelasan tentang pentingnya bahasa Arab, definisi puisi dan sejarah sastra Arab. Tahap selanjutnya adalah pertunjukan pembacaan puisi Arab dan musikalisasi puisi Arab yang dilakukan oleh dosen dan mahasiswa. Pada tahap small group discussion, beberapa dosen dari prodi Bahasa dan Sastra Arab menjadi mentor untuk beberapa kelompok siswa untuk menganalisis keindahan puisi Arab dan memadukannya dengan suara musik dari media yang telah disiapkan.

\section{Pelaksanaan Program}

Kegiatan PKM ini berlangsung pada tanggal 19 Maret di Pondok Pesantren Darul Muttaqin Kayu Agung Kabupaten OKI, Sumatera Selatan. Partisipan yang diharapkan hadir adalah seluruh siswa Madrasah Aliyah Pondok Pesantren Darul Muttaqin, baik putra maupun putri. Sementara penggiat PKM adalah dosen-dosen prodi Bahasa dan Sastra Arab; Muhammad Walidin, M.Hum., Drs, Masyhur, M.Ag., Ph.D, Munandar, Lc.,M.Ed., Ph.D, Faqihul Anam, M.Hum., dan seorang mahasiwa dari angkatan 2017 bernama Redo Fandea.

Dalam menyajikan narasi PKM ini, akan dibagi dalam 3 tahap. Pertama, lecturing, kedua Performance, dan ketiga small group discussion.

\section{Tahap lecturing}

Tahapan ini dimulai dengan mengenalkan urgensi mempelajari bahasa Arab, definisi puisi Arab dan sejarahnya oleh Redo Fandea; mahasiwa prodi Bahasa dan Sastra Arab angkatan 2017. Istilah-istilah dalam puisi Arab:

a. Definisi shi'r:

$$
\text { الثعر هو الكلام الموزون المرتبط بمعنى وقافية. }
$$

Al-Sbir huwa al-kala $>m$ al-mauz\} $u>n$ al-murtabit $\}$ bimakna wa qa $>$ fiyah

Artinya: Shi'r atau syair atau puisi Arab adalah ucapan yang memiliki wazan (pola timbangan; ritme), bermakna, dan diakhiri dengan sajak. 
b. Waz\}an berarti timbangan/pola-pola tertentu yang disebut dengan Bab\}ar atau matra/metrum/ritme. Ada 16 jenis bab\}ar yaitu bab\}ar basi>t\}, t\}awi\}l, rajz, ka>mil, ramal, madi $>$ d, khafi $>$ f, wa $>$ fir, mutada $>$ rik, hazaj, mutaqa $>$ rib, sari $>$; khafi $>f$, muns\}arih, mud $\} a>r a$, muqtad $\} a b$. Salah satu waz\}an yang dijadikan contoh di sini adalah bah\}ar rajaz. Berikut pola waz\} annya:

\begin{tabular}{|c|c|}
\hline مستفعلن مستفعلن & مستفعلن مستفعلن \\
\hline $0 / / 0 / 0 / \quad 0 / / 0 / 0 /$ & $0 / / 0 / 0 /$ \\
\hline Mustafilun Mustafilun & Mustafilun Mustafilun \\
\hline كا للؤلؤ الرطب العذب ب & يا ذالذي ألفاظه \\
\hline $0 / / 0 / 0 / \quad 0 / / 0 / 0 /$ & $0 / / 0 / 0 /$ \\
\hline Kal lu' lu’ir rat bil azib & Ya zal lazy al fa zu hu \\
\hline
\end{tabular}

c. Qa>fiyah adalah kata terakhir pada bait syair, yang dihitung mulai dari huruf yang terakhir pada bait sampai dengan huruf hidup sebelum huruf sukun yang ada di antara kedua huruf hidup tersebut. Sebagai contoh adalah bait berikut ini:

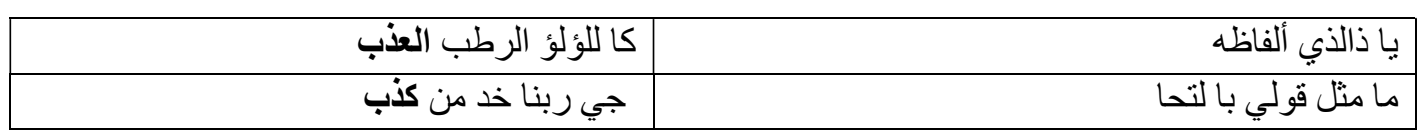

Gambar 1. Rido Fandea sedang presentasi mengenai bahasa dan puisi Arab

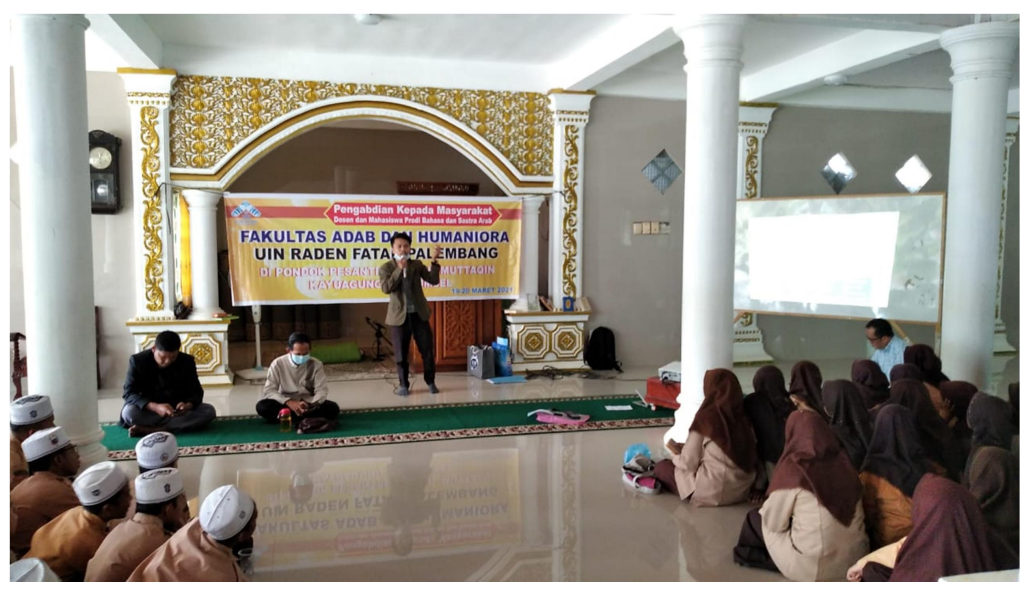

2. Tahap Performance

Tahap ini adalah kelanjutan dari tahap sebelumnya. Bila dalam presentasi telah diterangkan keindahan musikalitas puisi Arab, maka pada tahap ini dua orang presenter akan melakukan pertunjukan dengan pembacaan puisi Arab dari Penyair Turki Usmani yang bernama Nikolas alSaigh. Tahap pertama, dosen (Muhammad Walidin, M.Hum.) memberi perkenalan puisi kemudian dilanjutkan dengan musik pengiring. Terdapat jeda antara setiap syair yang dibacakan secara bergiliran oleh dosen dan mahasiswa. Dalam setiap jeda itu, diisi oleh musik pengiring yang 
bernuansa musik Timur Tengah dan India. Gabungan antara musik dan puisi mendatangkan perasaan yang syahdu, visual imajinatif, dan perasaan menyenangkan ketika mendengar puisi Arab.

a. Muhammad Walidin

PENDAHULUAN

Khalil bin Ahmad al-Farahidi

Kita patut berterima kasih pada tokoh ini

Ditelitinya syair-syair Arabi,

Mengapa nadanya begitu dan begini

Ia simpulkan bahwa syair syair Arabi

Memiliki timbangan ritmik nan surgawi

Lalu ia beri nama ilmu ini

Yang Anda kenal dengan Arud\} wal Qawa>fi,

Inilah salah satu timbangan ritmik berjenis bahar Rajaz Majzuk

Dari puisi Nikolas al-Saigh, salah satu penyair Turki Usmani

Selamat menikmati!

-Musik berjalan-bttps:/ / youtu.be/ dsf9toV wZg4

b. Redo Fandea

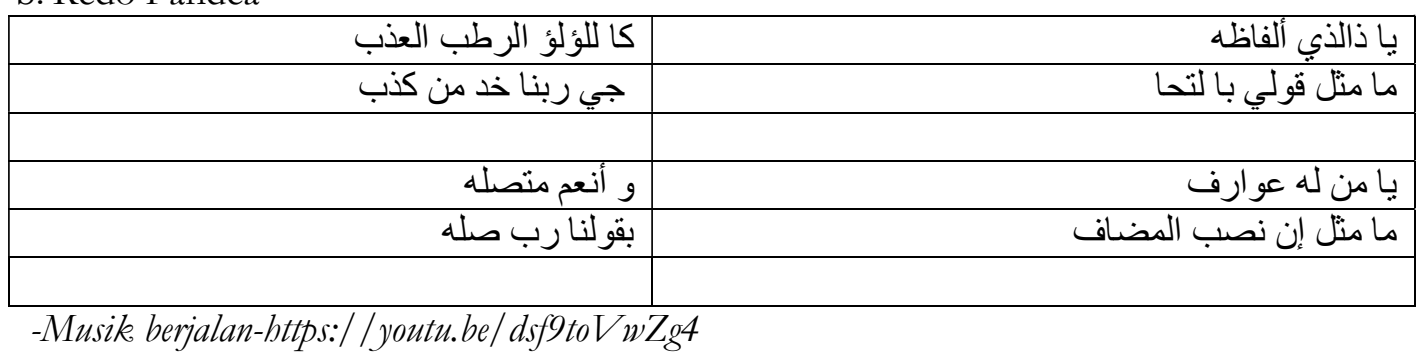

a. Muhammad Walidin, M.Hum.

\begin{tabular}{|c|c|}
\hline مدهبة مفضضه & نرجسة مضعفة \\
\hline أترجة معضضه & تحسب لو لا ريحها \\
\hline لؤُلؤة مرضضه & أورض ياقوت على \\
\hline أنفسنا محرضه & ماإنتني على الهوى \\
\hline
\end{tabular}

-Musik berjalan- bttps://youtu.be/dsf9toVwZg4

b. Redo Fandea

\begin{tabular}{|c|c|}
\hline فى علمه فاق الأنام & يا أبها القرم الذى \\
\hline جى قولنا مكره عام & ماد يضاهى فى التحا \\
\hline و الليل يقض نحبه & يمر بى وفد الصبا \\
\hline در عليه عشبه & مر بروض زاهر \\
\hline
\end{tabular}


-Musik berjalan- bttps:/ / youtu.be/dsf9toV wZg4

A dan b (Bersama-sama)

\begin{tabular}{|c|c|c|}
\hline \multicolumn{2}{|r|}{ نشوة من أحبه } & فخلته من طبيه \\
\hline
\end{tabular}

Gambar 2. Kedua presenter sedang membacakan puisi Arab diiringi musik

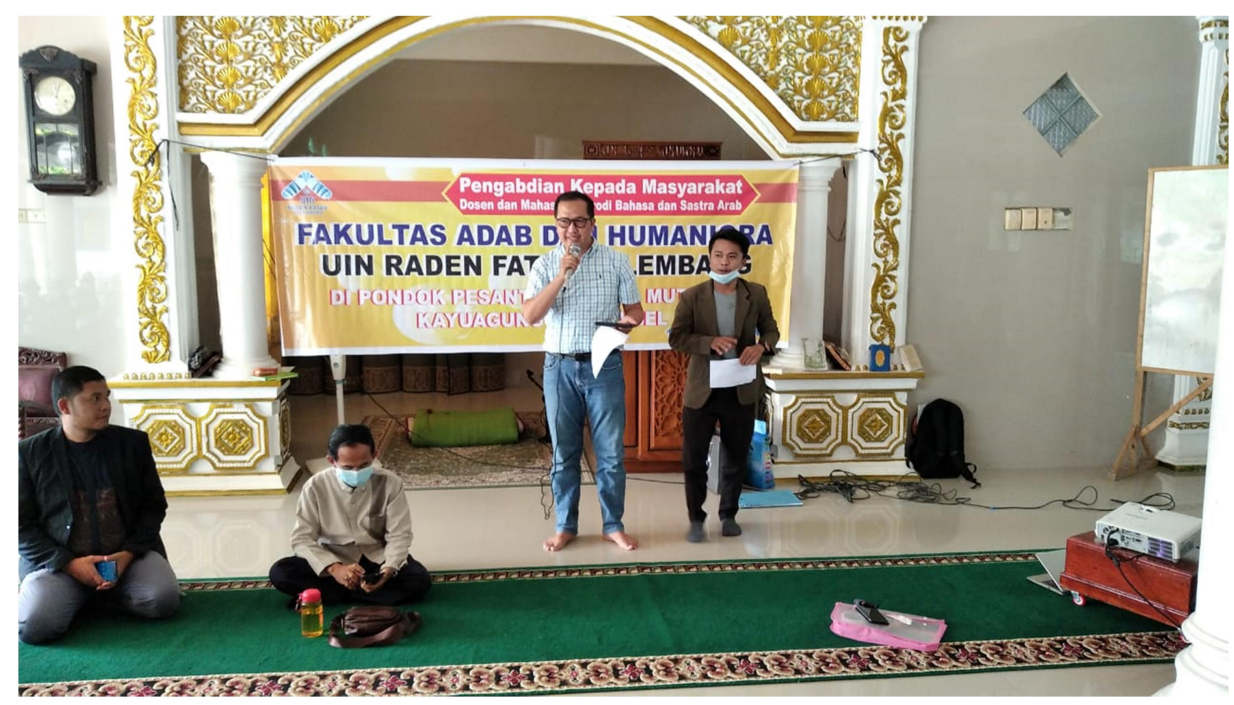

Penampilan puisi Arab ini diapresiasi oleh para siswa Madrasah Aliyah Pondok Pesantren Darul Muttaqin. Untuk lengkapnya, silakan unduh di channel youtube: https://youtu.be/5tEJ4ytNx$\underline{E}$

\section{Tahap Small Group Discussion}

Tahap ini perlu dilakukan untuk memperdalam bagaimana ritme dan irama yang ajeg bisa muncul dari puisi tersebut. Suara yang berbunyi dapat disesuaikan dengan ketukan tangan atau potongan bunyi sehingga menghasilkan resonansi suara merdu.

Group besar akan dipecah menjadi lima group kecil dengan anggota group sekitar 10 orang. Group 1 dipimpin oleh M. Walidin, M.Hum. Group 2 dikepalai oleh Drs. Masyhur, M.Ag., Ph.D., Group 3 dimotori oleh Munandar, Lc., M.Ed., Ph.D. Group 4 dikomandoi oleh Faqihul Anam, M.Hum., dan group 5 dikawal oleh Redo Fandea.

Setiap presenter akan mengajak anggota group untuk mencoba merasakan ketukan setiap suara puisi di atas. Kemudian, mereka diajak untuk memvisualisasikan vowel dan konsonan ke dalam tanda / untuk konsonan, dan tanda $\mathbf{0}$ untuk vowel. Lihat bagan berikut:

\begin{tabular}{|c|c|}
\hline كا للؤلؤ الرطب العذ ب & يا ذالذي ألفاظه \\
\hline $0 / / 0 / 0 / \quad 0 / / 0 / 0 /$ & $0 / / 0 / 0 /$ \\
\hline Kal lu' lu'ir rat bil azib & Ya zal lazy al fa zu hu \\
\hline $0 / / 0 / 0 /$ & $0 / / 0 / 0 /$ \\
\hline
\end{tabular}

Dari percobaan di atas, dapat diketahui bahwa pola timbangan/ritme di atas mengikuti pola: 


\begin{tabular}{|c|c|}
\hline مستفعلن مستفعلن & مستفعلن مستفعلن \\
\hline $0 / / 0 / 0 / \quad 0 / / 0 / 0 /$ & $0 / / 0 / 0 /$ \\
\hline Mustafilun Mustafilun & Mustafilun Mustafilun \\
\hline
\end{tabular}

Pola ini kemudian diganti dengan bahar wafir dengan pola :

\begin{tabular}{|c|c|}
\hline مفاعلتن مفاعلنت فعولن & مفاعلتن مفاعلتن فعولن \\
\hline $0 / 0 / / \quad 0 / / / 0 / / 0 / / / 0 / /$ & $0 / 0 / / \quad 0 / / / 0 / / 0 / / / 0 / /$ \\
\hline Mufa>latun Mufa>latun $\mathrm{Fa}^{\prime} \mathrm{u}>$ lun & Mufa>latun Mufa>latun $\mathrm{Fa}^{\prime} \mathrm{u}>$ lun \\
\hline
\end{tabular}

Selanjutnya, siswa akan diajak untuk menerapkan pola bunyi irama bahar wafir ini ke dalam syair yang familiar di telinga mereka yaitu, puisi berjudul al-I'tira $>f$ (Pengakuan) karya Abu Nawas.

\begin{tabular}{|c|c|}
\hline ولا أقوى على النار الجحيم & إلهي لست للفردوس أهلا \\
\hline فإنك غافر الذنب العظيم & فهب لي توبة واغفر ذنوبي \\
\hline فهب لي توبة يا ذا الجلال & ذنوبي منّل أعداد الرمال \\
\hline وذنبي زائد كيف احتمال & و عمري ناقص في كل يوم \\
\hline
\end{tabular}

Setelah diajak memperhatikan pola ritme puisi Abu Nawas, anggota group akan menyadari bahwa bunyi merdu dari puisi tersebut bersumber dari keteraturan bah \}ar wa $>$ fir yang menjadi polanya. Mereka juga akan sadar bagaimana sulitnya penyair menentukan diksi sehingga semua kata terpilih tunduk pada keselarasan bunyi sesuai pola waz\}annya.

\section{Refleksi Capaian Program}

Mengetahui keindahan puisi Arab bagi pelajar adalah kegiatan yang sangat menyenangkan. Pola-pola atau rumus-rumus yang tampak rumit pada saat teori ternyata menjadi mudah saat diaplikasikan ke dalam kegiatan praktek pembacaan puisi berdasarkan teori al-Arud\} wa al-Qawa $>$ fi. Sayangnya, kegiatan dalam sesi small group discussion tidak berjalan maksimal karena kekurangan waktu. Sesi ini diputuskan untuk diganti dalam kelas besar dengan pembelajaran klasikal. Walaupun demikian, penerima sasaran PKM merasakan senang dengan pembelajaran pembacaan puisi Arab sehingga mereka memiliki motivasi yang tinggi untuk rajin belajar bahasa Arab.

\section{Penutup}

Mempelajari bahasa Arab adalah tugas bagi pelajar yang memiliki matapelajaran bahasa Arab di sekolah masing-masing. Para guru/dosen selalu mencari cara bagaimana pelajaran bahasa Arab ini mudah diterima dan tinggi motivasi mempelajarinya. Berbagai metode pembelajaran telah diciptakan dan banyak cara untuk memotivasi pelajar agar semangat dan lebih mencintai bahasa Arab. Salah satu cara meningkatkan motivasi belajar bahasa Arab bagi siswa adalah dengan pembacaan puisi Arab. Puisi dikenal sebagai ekspresi dengan bahasa yang indah. Di samping itu, puisi, khususnya puisi Arab atau shiï memiliki pola-pola tertentu yang menghasilkan musikalitas. Unsur musikalitas inilah yang akan membawa perasaan senang bagi para pendengarnya. Dengan program PKM ini, diketahui siswa Madrasah Aliyah Pondok Pesantren Darul Muttaqin Kayuagung Sumatera Selatan 
mengalami peningkatan motivasi belajar bahasa Arab setelah mengikuti sesi program PKM dosen dan mahasiswa Prodi Bahasa dan Sastra Arab Fakultas Adab dan Humaniora UIN Raden Fatah Palembang.

\section{Daftar Pustaka}

Andangdjaja, Hartodjo. (1983). Puisi Arab Modern. Jakarta: Pustaka Jaya.

D\} aif, Shauqi. (n.d). al-Fann wa Madha > bibubu fi al-Shi'r al-Arabi. Kairo: Dar al-Ma'arif.

Kamil, Sukron. (2009). Teori Kritik Sastra Arab. Jakarta: Rajawali Pers.

Maryam, Siti. (2002) Sejarah Peradaban Islam Dari Masa Klasik Hingga Modern. Yogyakarta: Jurusan SPI Fakultas Adab dan Lesfi.

Umam, Chatibul. (1990). al-Muyassar fi ilm a-Arud. Jakarta: Hikmat Syahid.

Pradopo, Rachmat Djoko. (1997). Pengkajian Puisi. Yogyakarta: UGM Press.

Wajih, Makmun Abdul Halim. (2006). al-Aru $>d$ wa al-Qa $>$ fiyah Baina at-Tura $>$ sh wa at-Tajdi $>d$. Kairo:

Muassasah al-Mukhtar. 